\title{
Nutrition in Pregnancy
}

\author{
Surabhi Jain ${ }^{*}$ \\ Chief Nutritionist, Nutriwell India, Lucknow, India \\ *Corresponding Author: Surabhi Jain \\ Email: drsiyajain@gmail.com
}

\begin{abstract}
Nutrition plays a very vital role at all times in life. And rightly so, it does in pregnancy too. Along with providing sufficient nutrients to the mother's body, sufficient nutrients should reach the growing offspring as well. Nutrition in pregnancy is directly proportional to maternal as well as offspring health. Optimal nutrition ensures optimal foetal growth. It also ensures lesser risk of developing diseases later in life (especially chronic non-communicable diseases). This article aims to review nutritional requirements during pregnancy and focus on the consequences of improper nutritional intake.
\end{abstract}

Keywords: Nutrition, Gestational, Protein.

\section{Introduction}

The important recommendation is to have a healthy and balanced diet. However, there are some certain specifications about what not to have and what to have more of. Discussed below are some important nutrients needed during pregnancy, their food sources, recommended intake and deficiency risks. Below are also mentioned some other factors to be considered.

We reviewed 20 articles and all of studies have indicated that health behaviors such as dietary behavior \& smoking impacts both mother \& fetus health. ${ }^{1}$

Habits like smoking during pregnancy ${ }^{2}$ has shown to be associated with increased risk of infertility among female fetus and regarding nutritional deficiencies can lead to intra uterine growth retardation. ${ }^{3}$

In some studies healthy diet role has been discussed and it been specially pointed that more consumption of fish, olive oil, diary \& fruit \& vegetables were associated with decrease in depression test scores? ${ }^{4}$ Also, there are some evidences showing the decrease in upper respiratory tract infection among pregnant women with more fruit \& vegetable in their diet. ${ }^{5}$

Another article reported that diets including more fruit $\&$ vegetable have the most adequacies for 15 nutritional trace elements ${ }^{11}$ Optimum physical activity is associated with less depression and better mental health of the mother. ${ }^{6}$ In addition, lots of study illustrated that education \& giving the guidelines to pregnant women has a great impact on their behavior. And it can lead to a big change. ${ }^{10}$

Another research ${ }^{11}$ that has examined that effect of education by distributing a small leaflet about alcohol abstinence and proper diet guidance during pregnancy indicated that even the distribution of a simple educational leaflet has great effect in development of their attitude and behavior.

In particular all current research underscores that the first 1000 days of life (from conception up to two years of life) are crucial for the prevention of adulthood diseases ${ }^{11}$ and that specific maternal conditions during the periconceptional period (particularly obesity and excessive weight gain during pregnancy) are associated with high birth weight, obesity and alterations in glucose metabolism in children and, later, in adults, with increased cardiometabolic risk. ${ }^{12}$

\section{Nutrition in Pregnancy}

Even though the common belief may go as 'eating for two', it is not actually true. The mother just needs to eat a little more than she usually does. However, the diet should be abundant in nutrients and enough to nurture the mother and her growing foetus as well as for lactation for breastfeeding later.

Table 1: Balanced Diet for Pregnant Woman

\begin{tabular}{|r|l|c|}
\hline \multicolumn{3}{|c|}{ Sedentary Work } \\
\hline S. NO. & Food Group & Quantity in g \\
\hline 1 & Cereals and millets & 300 \\
\hline 2 & Pulses & 60 \\
\hline 3 & Milk(ml) & 500 \\
\hline 4 & Root and Tubers & 100 \\
\hline 5 & Green leafy vegetables & 150 \\
\hline 6 & Other vegetables & 100 \\
\hline 7 & Fruits & 200 \\
\hline 8 & Sugar & 20 \\
\hline 9 & Fats and oils (visible) & 30 \\
\hline
\end{tabular}

For Non-vegetarians $30 \mathrm{~g}$ of pulses can be substituted with $50 \mathrm{~g}$ of meat/chicken/fish/egg

Ref: ICMR recommended dietary allowance

\section{Energy and Macronutrients}

Energy requirements moderately increase during pregnancy. These increased requirements can be fulfilled by increasing the intake of energy along with symmetry with macronutrients. The additional energy requirements are relatively small. However, these shouldn't be consumed in excess either. Women who are overweight may not need to increase their energy intake. 
Table 2: Weight Gain In pregnancy

\begin{tabular}{|l|c|c|c|c|}
\hline \multirow{2}{*}{ Component } & \multicolumn{4}{c|}{ Period of Gestation } \\
\cline { 2 - 5 } & upto10 weeks & upto 20 weeks & upto 30 weeks & upto 40 weeks \\
\hline Foetus and placenta & 55 & 720 & 2350 & 4750 \\
\hline Uterus and breast & 170 & 765 & 1170 & 1300 \\
\hline Blood & 100 & 600 & 1300 & 1350 \\
\hline Extracellular water & - & - & - & 1200 \\
\hline Fat & 325 & 1915 & 3500 & 4200 \\
\hline Total & 650 & 4000 & 8320 & 12800 \\
\hline
\end{tabular}

Source: Passmore, P. Eastwood, M.A., Human Nutrition and Dieteics, English language Book Society/ Churchill Living Stone, 1986.

Less than half of total weight gain resides in the foetus, placenta and amniotic fluid. The increasing subcutaneous fat in abdomen and thighs serves as energy reserve during pregnancy and lactation. By full term, average weight gain during pregnancy for a normal healthy woman with desirable body weight is $12.5 \mathrm{~kg}$ ranging between $11-13 \mathrm{~kg}$. The pattern of weight gain is as important as total weight gain. During first trimester there is little increase in weight $(0.7$ to $1.4 \mathrm{~kg}$ ). Thereafter a steady gain of $0.4 \mathrm{~kg} /$ week is desirable. $^{19}$

\section{Gestational weight gain and nutrition}

Various factors determine the gestational weight. The amount of weight gained during pregnancy greatly affects the baby.

1. Women that are underweight (BMI < 18.5) will gain around 12.5 to $18 \mathrm{kgs}$ in the course of their whole pregnancy.

2. Women that have normal weight (BMI 18.5 to 24.9) will gain around 11.5 to $16 \mathrm{kgs}$ in the course of their whole pregnancy. And a weight gain of around 17 to $25 \mathrm{kgs}$ if the pregnant woman is carrying twins.

3. Women who are overweight (BMI 25 to 19.9) will gain around 7 to $11.5 \mathrm{kgs}$ in the course of their whole pregnancy. The weight gain increases to 14 to $23 \mathrm{kgs}$ if the woman is carrying twins.

4. Obese women (BMI > 30) will gain around 5 to $9 \mathrm{kgs}$ in the course of their whole pregnancy. It will increase to 11 to $19 \mathrm{kgs}$ if the woman is carrying twins.

5. In order to maintain healthy gestational weight and avoid further pregnancy complications, adequate nutrition is of utmost importance. Consistent nutritional intake in accordance with the guidelines will help prevent too much or too little weight gain.

For a reference Indian woman (ICMR 1990) weighing 50kg, the total energy cost of pregnancy has been estimated to be $73000 \mathrm{kcal}$. This includes the energy required for deposition of $4 \mathrm{~kg}$ of body fat $(36000 \mathrm{kcal})$ to be utilized later during lactation. Considering the increased energy demand during lactation and beneficial effect of increased energy intake on birth weight of infants and also protein sparing action, an additional intake of 300k.cal.per day during pregnancy is recommended. ${ }^{21}$
Table 3: ICMR recommended dietary allowances for an expectant mother

\begin{tabular}{|l|c|c|}
\hline Nutrient & $\begin{array}{c}\text { Normal Adult } \\
\text { Woman }\end{array}$ & $\begin{array}{c}\text { Pregnant } \\
\text { Woman }\end{array}$ \\
\hline Energy $(\mathrm{k} . c \mathrm{cal})$ & 1875 & \\
Sedentary & 2225 & 2175 \\
Moderate & 2925 & 2525 \\
Heavy & 50 & 3225 \\
Protein(g) & 20 & 65 \\
Fat $(\mathrm{g})$ & 400 & 30 \\
Calcium(mg) & 30 & 1000 \\
Iron(m) & & 38 \\
Vitamin A & 600 & 600 \\
Retinol $(\mu \mathrm{g})$ & & \\
(or) & 2400 & 2400 \\
$\beta$ carotene $(\mu \mathrm{g})$ & & \\
Thiamine $(\mathrm{mg})$ & 0.9 & 1.1 \\
Sedentary & 1.1 & 1.3 \\
Moderate & 1.2 & 1.4 \\
Heavy & & \\
Riboflavin(mg) & 1.1 & 1.3 \\
Sedentary & 1.3 & 1.5 \\
Moderate & 1.5 & 1.7 \\
Heavy & & 14 \\
Niacin(mg) & 12 & 16 \\
Sedentary & 14 & 18 \\
Moderate & 16 & 400 \\
Heavy & 2.0 & 1 \\
Pyridoxine(mg) & 40 & \\
Ascorbic acid(mg) & & \\
Folic acid $(\mu \mathrm{g})$ & & \\
Vitamin $\mathrm{B}_{12}(\mu \mathrm{g})$ & & \\
\hline
\end{tabular}

\section{Protein}

Both the mother and the foetus require protein in maximum amount during the second and third trimester. As per the joint $\mathrm{FAO} / \mathrm{WHO} / \mathrm{UNU}$ recommendation, an increased intake of protein is required per day. In order to maintain maternal tissues and foetal growth, to support protein synthesis, protein is required in more amounts. Dairy products, beans and legumes, eggs, lean meat, nuts are great sources of protein for pregnant women. The current Estimated Average Requirement and RDA 
recommendations of 0.88 and $1.1 \mathrm{~g} \cdot \mathrm{kg}^{-1} \cdot \mathrm{d}^{-1}$, respectively, are for all stages of pregnancy. The single recommendation does not take into account the changing needs during different stages of pregnancy.

An additional protein intake of $15 \mathrm{~g} /$ day i.e. a total of $65 \mathrm{~g}$ is recommended. ${ }^{21}$

Table 4: Portion Size of Food and Nutrient Content

\begin{tabular}{|c|c|c|c|c|c|}
\hline Food groups & g/portion & Energy (kcal) & Protein & Carbohydrate & Fat \\
\hline Cereals and Millets & 30 & 100 & 3.0 & 20 & 0.8 \\
\hline Pulses & 30 & 100 & 6.0 & 15 & 0.7 \\
\hline Egg & 50 & 85 & 7.0 & - & 7.0 \\
\hline Meat/chicken/fish & 50 & 100 & 9.0 & - & 7.0 \\
\hline $\operatorname{Milk}(\mathrm{ml})^{*}$ & 100 & 70 & 3.0 & 5 & 3.0 \\
\hline Roots and Tubers & 100 & 80 & 1.3 & 18 & - \\
\hline Green leafy vegetables & 100 & 45 & 3.6 & - & 0.4 \\
\hline Other vegetables & 100 & 30 & 1.7 & - & 0.2 \\
\hline Fruits & 100 & 40 & - & 10 & - \\
\hline Sugar & 5 & 20 & - & 5 & - \\
\hline Fats and Oils (Visible) & 5 & 45 & - & - & 5.0 \\
\hline
\end{tabular}

*Toned milk

Source: Dietary guidelines for Indians- a manual, NIN, ICMR, 1999.

\section{Fat and essential fatty acids}

Fats are necessary for structural and metabolic functions as well as for the transportation of fat soluble vitamins. Nuts, vegetable oil, seeds and oily fish are excellent sources to have good fats from. Even though there is now such recommendation so as how much fat pregnant women should have, it is advised that they have them in adequate amounts.

ICMR expert committee has suggested an intake of $30 \mathrm{~g}$ of visible fat/day during pregnancy. It is important for omega-3 fatty acids to be supplied to the fetus in adequate amounts throughout pregnancy. To optimize pregnancy outcomes and fetal health, consensus guidelines have recommended that pregnant women consume at least 200 mg of DHA per day. ${ }^{18}$

\section{Carbohydrates}

There is no need to increase consumption of starch, sugar and non-starch polysaccharides during pregnancy. Constipation is a common symptom that is observed during pregnancy. So, to combat constipation and regulate bowel movements, it is advised to consume dietary fiber in good amounts along with plenty of fluids. Around 12 to 24 grams of dietary fiber should be had daily. Good sources of fibre include whole grains (in variety), carrots, broccoli, and beans.

\section{Vitamins}

The need for each type of vitamin is discussed below:

\section{Vitamin A}

The intake of this vitamin is to be increased during pregnancy; especially during the third trimester. For proper growth and maintenance of the foetus and for maternal tissue growth, the mother's intake of vitamin A should be sufficient. However, vitamin A consumption shouldn't be increased in very large amounts; small amounts are sufficient.

Disproportionate intake of Vitamin A in the form of retinol can prove to be toxic to the foetus. Extra intake of Vitamin A in the form of carotenes does not pose any risk. Carotenes can be had from carrots, sweet potatoes, spinach, cantaloupe etc.

Vitamin A requirements during pregnancy have been computed based on the vitamin A content of liver of the newborn. The additional intake works out to $25 \mu \mathrm{g} / \mathrm{day}$ throughout pregnancy. ${ }^{21}$

\section{Vitamin C}

Moreover the recommendation for a normal adult woman, $40 \mathrm{mg} /$ day, includes a margin of safety. ICMR, therefore, has not recommended any additional intake of vitamin $\mathrm{C}$ during pregnancy. Hence, sufficient amount of vitamin $\mathrm{C}$, along with a little elevation in it, needs to be had by pregnant women. Oranges, lemon, strawberry, watermelon, mangoes, kiwi, cantaloupe and pineapple are excellent sources to keep vitamin $\mathrm{C}$ levels in check.

Vitamin $\mathrm{C}$ deficiency in expecting mothers can cause brain damage to the foetus.

\section{Vitamin D}

Vitamin D can be obtained from food sources such as eggs, fatty fish etc. But, it is best to have your dose of Vitamin D from exposure to sunlight. It is of utmost importance to have sufficient Vitamin D during pregnancy to ensure proper absorption as well as utilization of calcium, calcification of the foetal skeleton. It is also important to have this vitamin in sufficient amounts to prevent the problem of reduced bone mass in the offspring. It is also needed for calcium synthesis. 
Women with low vitamin D levels are at a higher risk of developing preeclampsia. It can also lead to abnormal bone growth in the offspring.

\section{Folate}

Pregnant women are recommended to have folate supplements. Folic acid can prevent birth defects such as spina bifida. This B group vitamin is necessary for proper growth and development. Naturally found in green leafy vegetables and citrus fruits, its supplements are also recommended to pregnant women. The recommended dose of folic acid is $400 \mathrm{mcg}$ per day. It is $600 \mathrm{mcg}$ from months four to nine and $500 \mathrm{mcg}$ while breastfeeding. This vitamin is also required for DNA replication.

Its deficiency can cause anaemia in the mothers and congenital abnormalities in the foetuses.

\section{Calcium}

The calcium requirement for an adult woman is $400 \mathrm{mg} / \mathrm{day}$. During pregnancy the need increases to $1000 \mathrm{mg} /$ day.To maintain bone mineral density and bone mass, calcium is needed. Pregnant women have an increased need for calcium. Placenta does the work of transportation of calcium. By the time a woman is in the $20^{\text {th }}$ week of her pregnancy, calcium levels are higher in the foetus than in the maternal plasma. The calcium needs of a lactating woman are also high. Best sources of calcium are milk and milk products, followed by green leafy vegetables.

Enough calcium intake reduces the risk of preeclampsia. Calcium deficiency can also give rise to various complications in the growing foetus.

\section{Iron}

The requirement of iron increases from $30 \mathrm{mg} /$ day to $38 \mathrm{mg} /$ day during pregnancy. The increased requirement of $8 \mathrm{mg} /$ day is due to the expansion of maternal tissues including red cell mass and to build the iron store in foetal liver to last for at least 4-6 months after birth. This is because the baby's first food milk is deficient in iron. Generally infants are born with a high level of iron, 18-22g/ $100 \mathrm{ml}$

Since the volume of blood increases in the maternal body and the blood and oxygen is supplied to the foetus by the body, a lot more iron is required by pregnant women. A pregnant woman needs almost twice as much iron than a non-pregnant woman. Pregnant women should have plenty of foods such a green leafy vegetables, dry fruits and nuts,

beetroot, pomegranate, seeds, beans and lentils to fulfil their daily iron requirements. If needed, iron supplementation is recommended.

Deficiency of iron can result in anaemia, low birth weight and premature birth. Inadequate iron intake during pregnancy can also affect the growth and development of the foetus.

\section{Thiamine, Riboflavin, Niacin}

The RDA for thiamine, riboflavin and niacin is estimated on the same basis as for a normal adult woman ie., $0.5 \mathrm{mg} / 1000$ kcal, 0.6mg/ 1000k.cal and 6.6mg/1000k.cal respectively.

\section{Pyridoxine}

Pyridoxine needs are increased during pregnancy. The ICMR committee has suggested an intake of $2.5 \mathrm{mg}$ of vitamin B6 during pregnancy, an increase of $0.5 \mathrm{mg}$ per day.

\section{Vitamin B12}

Based on the vitamin B12 content of foetus, the demand for this vitamin is estimated to be nearly $0.3 \mu \mathrm{g} /$ day. ICMR has suggested an additional allowance of $0.5 \mu \mathrm{g}$ recommending a total daily intake of $1.5 \mu \mathrm{g}$ of Vitamin B12 during pregnancy.

\section{Other factors to consider \\ Smoking}

Pregnant women should completely abstain from smoking; passive smoking applies here too. Smoking can have adverse effects on the foetus as well as to maternal health. These negative effects of smoking also go way beyond just childhood. Along with negative effects in the offspring, smoking also causes various complications to the pregnancy. Not just pregnancy, smoking also affects breastfeeding. It is associated with lower levels of DHA in maternal plasma as well as breast milk. Almost $20 \%$ of children who were exposed to smoke as foetuseshave increased chances of developing asthma and bronchospasm.

\section{Obesity}

Women in their childbearing age who suffer from obesity have higher chances of complications during pregnancy. Hence, it is important to maintain a normal body weight when trying to conceive to avoid further complications.

\section{Caffeine}

Limiting caffeine or even better, avoiding it is best during pregnancy. Caffeine crosses the placenta into amniotic fluid and also the foetus's bloodstream. The effects of caffeine can negatively affect the foetus.

\section{Physical activity}

Physical activity during pregnancy is essential to ensure a healthy pregnancy, maintaining weight gain and preparing the mother's body for labour.

\section{Effects of poor nutrition or inadequate nutrition during pregnancy}

Mothers who eat a nutrient deficit diet during their pregnancy are very likely to put their children at a very high risk of developing long term and serious health issues. These various health issues range from heart diseases, hypertension, lower IQ to neural tube defects. A mother's diet is very important when it comes to the long term health 
of the offspring. The offspring may also have birth defects and improper growth.

\section{Conclusion}

With all the points discussed above, we come to the conclusion that nutrition in pregnancy plays a very integral role in the mother's as well as the offspring's wellbeing. A healthy pregnancy and childbirth cannot be achieved with nutrition playing the main part in it.

A well balanced, nutrition rich and varied diet is necessary right from the pre-conceptional period. Proper diet, coupled with physical exercise, lifestyle modifications and mental wellbeing is the key to a healthy and happy pregnancy. The diet should be in accordance with the recommendation guidelines and devoid of anything that is meant to be avoided.

\section{Source of Funding: None.}

\section{Conflict of Interest: None.}

\section{References}

1. Ye X, Skjaerven R, Basso O, Baird DD, Eggesbo M, Cupul Uicab LA. In utero exposure to tobacco smoke and subsequent reduced fertility in females. Hum Reprod 2010; 25:2901-6.

2. Da Motta Gde C, Echer IC, Lucena Ade F. Factors associated with smoking in pregnancy. Rev Lat Am Enfermagem 2010;18:809-15.

3. Wen LM, Flood VM, Simpson JM, Rissel C, Baur LA. Dietary behaviours duringpregnancy: findings from first-time mothers in southwest Sydney, Australia. Int J Behav Nutr Phys Act. 2010;7:13.

4. Okubo H, Miyake Y, Sasaki S, Tanaka K, Murakami K, Hirota Y. Nutritional adequacy of three dietary patterns defined by cluster analysis in 997 pregnant Japanese women. Public Health Nutr 2011;14:611-21.

5. Chang MW, Nitzke S, Guilford E, Adair CH, Hazard DL. Motivators and barriers to healthful eating and physical activity among low-income overweight and obese mothers. $J$ Am Diet Assoc 2008;108:1023-8.

6. Li L, Werler MM. Fruit and vegetable intake and risk of upper respiratory tract infection in pregnant women. Public Health Nutr 2010;13:276-82.

7. Gollenberg A, Pekow P, Markenson G, Tucker KL, ChasanTaber L. Dietary behaviors, physical activity, and cigarette smoking among pregnant Puerto Rican women. Am J Clin Nutr 2008;87:1844-51.
8. Okoli CT, Greaves L, Bottorff JL, Marcellus LM. Health care providers' engagement in smoking cessation with pregnant smokers British Columbia. J Obstet Gynecol Neonatal Nurs 2010;39:64-77.

9. Bowden JA, Oag DA, Smith KL, Miller CL. An integrated brief intervention to address smoking in pregnancy. Acta Obstet Gynecol Scand 2010;89:496-504.

10. Crozier SR, Robinson SM, Borland SE, Godfrey KM, Cooper C, Inskip HM. Do women change their health behaviours in pregnancy? Findings from the Southampton Women's Survey. Paediatr Perinat Epidemiol 2009;23:446-53.

11. Adair L.S. Long-term consequences of nutrition and growth in early childhood and possible preventive interventions. Nestlé Nutr. Inst. Workshop Ser 2014;78:111-120.

12. Berti C., Cetin I., Agostoni C., Desoye G., Devlieger R. Emmett P.M et al. Pregnancy and infants' outcome: Nutritional and metabolic implications. Crit. Rev Food Sci Nutr 2016; 56:82-91. doi: 10.1080/10408398.2012.745477.

13. C. S. Williamson, Nutrition in pregnancy, British Nutrition Foundation, London, U.K.

14. Franca Marangoni, Irene Cetin, Elvira Verduci, Giuseppe Canzone, Marello Giovanni, Paolo Scollo et al. Maternal Diet and Breastfeeding, an Italian consensus document, $P M C$.

15. Kate Keenan, Thad Q Barlett, Mark Nijland, Jesse S Rodriguez, Peter W Nathanielsz, Nicole R Zurcher. Poor nutrition during pregnancy and lactation negatively affects neurodevelopment of the offspring: evidence from a transitional primate model

16. Francine Juhasz, The effects of poor nutrition on a foetus, www.livestrong.com

17. WHO/FAO/UNU. Protein and amino acid requirements in human nutrition. Report of a joint WHO/FAO/UNU Expert Consultation. World Health Organ Tech Rep Ser 2007;935:103-33

18. Jensen CL. Effects of n-3 fatty acids during pregnancy and lactation. Am J Clin Nutr 2006;83(6):1452-7.

19. A Manual of second Regional workshop on "Planning diet for health" 1999. Jointly organized by Dept. of Homescience. Womens Christian College and Indian Dietetic Association Madras Chapter.

20. Devadas, R.P., Dietary Guidelines, Avinashilingam Deemed University, Coimbatore, 641043, 1995.

21. Dietary Guidelines for Indians - A manual, National Institute of Nutrition, ICMR, Hyderabad, India, 1999.

How to cite this article: Jain S. Nutrition in Pregnancy J Nutr Metab Health Sci 2019;2(4):108-12. 